\title{
The Levels of Interferon-gamma Release as a Biomarker for Non-small-cell Lung Cancer Patients Receiving Immune Checkpoint Inhibitors
}

\author{
TOMONORI HIRASHIMA ${ }^{1}$, TOMOHIRO KANAI ${ }^{1}$, HIDEKAZU SUZUKI $^{1}$, HIROKO YOSHIDA $^{2}$, \\ AKANE MATSUSHITA ${ }^{2}$, HIROMI KAWASUMI ${ }^{2}$, YUMIKO SAMEJIMA ${ }^{1}$, YOSHIMI NODA ${ }^{1}$, \\ SHINGO NASU $^{1}$, AYAKO TANAKA ${ }^{1}$, NAOKO MORISHITA ${ }^{1}$, SHOJI HASHIMOTO ${ }^{3}$, \\ KUNIMITSU KAWAHARA $^{4}$, YOSHITAKA TAMURA ${ }^{2}$, NORIO OKAMOTO $^{1}$ and TOSHIO TANAKA ${ }^{3}$ \\ ${ }^{1}$ Department of Thoracic Oncology, ${ }^{2}$ Department of Clinical Laboratory, ${ }^{3}$ Department of Allergy, \\ and ${ }^{4}$ Department of Clinical Pathology, Osaka Habikino Medical Center, Osaka, Japan
}

\begin{abstract}
Background/Aim: The present study aimed to prospectively examine the usefulness of interferon-gamma (IFN$\gamma)$ release (IGR) as a biomarker in non-small-cell lung cancer patients receiving immune checkpoint inhibitor treatment (ICITx). Patients and Methods: IGR was measured using enzymelinked immunosorbent assay at four time points: within 14 days before ICI-Tx (T1), and 8 53 (T2), $22 \pm 7$ (T3), and $43 \pm 7$ (T4) days after ICI-Tx. Results: Twenty-nine patients were divided into three groups based on IFN- $\gamma$ levels in the IGR-positive control: Group-1 $(n=8)$ with $<10 \mathrm{IU} / \mathrm{ml}$ at T1, Group-2 $(n=12)$ with a decrease in IFN- $\gamma$ levels to $<10 \mathrm{IU} / \mathrm{ml}$ at T3 and/or T4, and Group-3 (n=9) without changes in IFN- $\gamma$ levels. Early progression and ICI-induced interstitial pneumonitis were frequently observed in Group-1 and Group-2, respectively. Group-3 exhibited more treatment cycles than the other groups. All three groups showed clear differences in clinical outcomes. Conclusion: IFN- $\gamma$ levels could be a biomarker for ICI-TX.
\end{abstract}

After the programmed cell death-1 (PD-1) gene was cloned (1), an anti-PD-1 antibody (2) was rapidly developed as an immune checkpoint inhibitor (ICI). ICIs have since become very important anticancer agents (3-5). However, there is currently no other biomarker for non-

This article is freely accessible online.

Correspondence to: Tomonori Hirashima, MD, Department of Thoracic Oncology, Osaka Habikino Medical Center, 3-7-1 Habikino, Habikino City, Osaka 583-8588, Japan. Tel: +81 729572121, Fax: +81 729578002, e-mail: hirashimat@ra.opho.jp

Key Words: Non-small-cell lung cancer, biomarker, interferongamma release assay, immune checkpoint inhibitors, immunerelated adverse events, interstitial pneumonitis. small-cell lung cancer (NSCLC) than programmed deathligand 1 (PD-L1) (6).

Recently, we have reported on NSCLC patients who developed pulmonary Mycobacterium tuberculosis (MTB) infection while receiving nivolumab (7). We have shown that the development of this paradoxical response closely resembles that of pseudo progression after ICI treatment. Furthermore, several studies (8-10) have indicated that the PD-1/PD-L1 axis and interferon-gamma (IFN- $\gamma$ ) are very important for cellular immunity to $M T B$. The interferon-gamma release assay (IGRA) is widely used as a diagnostic method for latent $M T B$ infection (11). The QuantiFERON ${ }^{\circledR}$-TB Test is an IGRA that can measure IFN- $\gamma$ released from $\mathrm{T}$ lymphocytes by whole bloodbased enzyme-linked immunosorbent assay (ELISA). We hypothesized that changes in the PD-1/PD-L1 axis by ICI treatment affect IFN $-\gamma$ release by $\mathrm{T}$ lymphocytes. Thus, the aim of the present prospective observational study was to verify our hypothesis and to examine the usefulness of monitoring IFN$\gamma$ as a biomarker in patients with NSCLC who are receiving ICI treatment.

\section{Patients and Methods}

Ethics. This study was approved by our institutional review board (approval no.: 884). All patients who participated in this study were enrolled after providing their written informed consent. Furthermore, this study was registered in the University Hospital Medical Information Network Clinical Trials Registry (UMIN000031881).

Patients. Patients with NSCLC were enrolled in this study between July 17, 2018 and February 25, 2019 at Osaka Habikino Medical Center. The main eligibility criteria were as follows: patients who were diagnosed with recurrent, unresectable stage III or IV NSCLC with measurable lesions, who received subsequent ICIs, such as nivolumab, pembrolizumab, and atezolizumab, without other concomitant anticancer therapies, and who had agreed to participate 
in this study by written informed consent. Other eligibility criteria included an age $\geq 20$ years and Eastern Cooperative Oncology Group (ECOG) performance status of $0-2$. The exclusion criteria were as follows: patients who had synchronous double tumors, had active infectious or hepatic disease, intended to become pregnant, or were deemed by a physician to be ineligible for the study.

Baseline patient characteristics and demographics. The baseline patient characteristics and demographics examined before ICI treatment were sex, age, smoking status, ECOG performance status, body weight, height, body mass index (BMI), medications, disease complications, past history, and history of cancer treatment.

Interferon-gamma release assay. The IGRA was performed in-house with the QuantiFERON ${ }^{\circledR}$-TB Gold Plus (QFT-Plus; Qiagen, Germany) assay, according to the manufacturer's instructions (12). The QFT-Plus test was performed in two stages. First, whole blood was collected into QFT-Plus blood collection tubes, which included a Nil Control tube (NC: negative control tube), Tuberculosis 1 (TB1) antigen tube, TB2 antigen tube, and Mitogen tube (PC: positive control tube). The PC in QFT-Plus contained phytohemagglutinin (PHA), which is a mitogen used in the diagnosis of primary immunodeficiency syndrome (13). Each tube was strictly incubated at $37^{\circ} \mathrm{C}$ for $20 \pm 0.5 \mathrm{~h}$. Second, after incubation, the samples were returned to room temperature $\left(17-27^{\circ} \mathrm{C}\right)$ and centrifuged at 2000 $3000 \times g$ for $15 \mathrm{~min}$. The plasma was collected, clarified by recentrifugation, and subjected to an ELISA using the QFT-Plus kit. The absorbance was read at wavelengths of 450 and $650 \mathrm{~nm}$.

Sample collection for IGRA. Sampling was performed during routine clinical procedures. Relative to treatment day (day 1), venous blood samples were collected for the IGRA at three time points, namely within 14 days before treatment (T1: day -14 to 1), on day $22 \pm 7$ (T3: day 15 to 29 ), and on day $43 \pm 7$ (T4: day 36 to 50) after treatment. After a protocol amendment, an additional time point for collection of the IGRA samples was added on day $8 \pm 3$ (T2: day 5 to 11 ). However, the T2 IFN- $\gamma$ levels were not used to categorize the enrolled patients.

Driver gene analysis and PD-L1 staining. The presence of epidermal growth factor receptor mutations was examined using the peptide nucleic acid-locked nucleic acid polymerase chain reaction clamp method (LSI Medience Corporation Central Laboratory, Tokyo, Japan). Anaplastic lymphoma kinase (ALK) fusion was detected using Optiview ALK (D5F5) (Roche Diagnostics, K.K., Tokyo, Japan). ROS proto-oncogene 1, receptor tyrosine kinase (ROS1) fusion was detected using the AmoyDx ROS1 Fusion Test Kit (Riken Genesis Co LTD, Tokyo, Japan). PD-L1 expression was determined using the PD-L1 IHC 22C3 pharmDx Dako kit (Agilent Technologies, Santa Clara, CA, USA).

Laboratory tests. The following blood and biochemical tests were regularly performed on samples from T1, T2, T3, and T4: cell counts (white blood cells, lymphocytes, and neutrophils), serum albumin, blood urea nitrogen (BUN), creatinine, and C-reactive protein (CRP). The neutrophil-to-lymphocyte ratio (NLR) was calculated by dividing the neutrophil count by the lymphocyte count.

Administration of immune checkpoint inhibitors. Nivolumab was intravenously administered at $3 \mathrm{mg} / \mathrm{kg}$ every 2 weeks between July
1 and August 31, 2018. After amendment of the approved dosage, $240 \mathrm{mg} /$ person were administered intravenously every 2 weeks from September 1, 2018. Pembrolizumab and atezolizumab were intravenously administered at $1200 \mathrm{mg} /$ person every 3 weeks and $200 \mathrm{mg} /$ person every 3 weeks, respectively.

Assessment of response and adverse events. Regarding the assessment of response and adverse events, the observation period was 12 weeks after the first ICI dosage. Tumor responses were assessed by a Tumor Board after each treatment cycle to determine whether the patients could receive the next cycle of treatment. We assessed clinical responses according to the Response Evaluation Criteria in Solid Tumors (RECIST) guideline version 1.1 and the immune-related RECIST guideline. In this study, the responses were categorized as complete response (CR), partial response (PR), stable disease (SD), progressive disease (PD), and not evaluable (NE). The severities of adverse events were graded according to the National Cancer Institute Common Terminology Criteria for Adverse Events, version 4.0 (14). The number of treatment cycles was counted until May 31, 2019.

Bronchoalveolar lavage, flow cytometry, and transbronchial lung biopsy. Bronchoalveolar lavage (BAL) was performed if the patient developed suspicious interstitial pneumonitis (IP). The tip of the bronchoscope was placed into the affected segment of the lung in patients with peripheral opacities. Fifty milliliters of sterile physiological saline were instilled through the bronchoscope, and BAL fluid (BALF) was retrieved by gentle hand suction applied to each syringe. The procedure was repeated three times and pooled BALF was centrifuged at $250 \times g$ for $10 \mathrm{~min}$ to collect the cells. Subsequently, the cell preparation was examined by flow cytometry using the same method as described in a previous report (15). A transbronchial lung biopsy (TBLB) was performed after collecting BALF, as described previously (16).

Statistical analysis. The primary goal of this study was to examine the correlation between the levels of IFN- $\gamma$ and clinical outcomes in NSCLC patients treated with ICI. In this study, we hypothesized that patients with CR, PR, or hyper-progressive disease (HPD) would be immunologically activated by ICI (RG: Reaction group) and those with PD, but not HPD or SD, would not (NRG: nonReaction group). Based on the study by Ferrara et al. (17), the RG and NRG would be expected to comprise $33 \%$ and $67 \%$ of the enrolled patients, respectively. We assumed that $60 \%$ of the RG and $10 \%$ of the NRG would show some type of immunological reaction as assayed by the IGRA. Subsequently, at least 28 patients were required to be able to reject the null hypothesis at $p<0.05$ and a power of $85 \%$. Under the assumption that approximately two patients would withdraw/drop out of the study, a minimum of 30 patients needed to be enrolled. All analyses were conducted using the statistical software package R (18). The patient background data were compared using the chi-square test and Fisher's exact test for categorical variables. A difference was considered statistically significant if the $p$-value was below 0.05 .

\section{Results}

Patient demographics. Thirty-one patients were enrolled in this study. Two patients were excluded because one did not receive ICI treatment due to disease progression and the other withdrew study consent. The first patient received ICI 
Table I. Patient demographics and laboratory data before immune checkpoint inhibitor treatment grouped according to interferon-gamma status in positive control.

\begin{tabular}{|c|c|c|c|c|}
\hline Variables & Total $(n=29)$ & Group-1 $(n=8)$ & Group-2 $(\mathrm{n}=12)$ & Group-3 $(n=9)$ \\
\hline \multicolumn{5}{|l|}{ Gender } \\
\hline Male & 24 & 8 & 9 & 7 \\
\hline Female & 5 & 0 & 3 & 2 \\
\hline \multicolumn{5}{|l|}{ Age } \\
\hline Median (range) & $73(44-83)$ & $69.5(55-83)$ & $74.5(57-84)$ & $73(44-79)$ \\
\hline \multicolumn{5}{|l|}{ Performance status } \\
\hline 0 & 2 & 0 & 1 & 1 \\
\hline 1 & 17 & 3 & 7 & 7 \\
\hline 2 & 10 & 5 & 4 & 1 \\
\hline \multicolumn{5}{|l|}{ Histology } \\
\hline Adenocarcinoma & 24 & 6 & 10 & 8 \\
\hline Squamous cell carcinoma & 3 & 1 & 1 & 1 \\
\hline Others & 2 & 1 & 1 & 0 \\
\hline \multicolumn{5}{|l|}{ Stage } \\
\hline IIIB-C & 3 & 1 & 1 & 1 \\
\hline IV & 18 & 4 & 9 & 5 \\
\hline Recurrence & 8 & 3 & 2 & 3 \\
\hline \multicolumn{5}{|c|}{ Previous corticosteroid treatment } \\
\hline Yes & 3 & 0 & 0 & 3 \\
\hline No & 26 & 8 & 12 & 6 \\
\hline \multicolumn{5}{|l|}{ PD-L1 staining } \\
\hline$<1 \%$ & 6 & 2 & 3 & 1 \\
\hline$>1 \%,<50 \%$ & 6 & 1 & 1 & 4 \\
\hline$>50 \%$ & 15 & 5 & 7 & 3 \\
\hline Unknown & 2 & 0 & 1 & 1 \\
\hline \multicolumn{5}{|l|}{ Driver mutation } \\
\hline Yes $^{\mathrm{a}}$ & 1 & 1 & 0 & 0 \\
\hline No & 28 & 7 & 12 & 9 \\
\hline \multicolumn{5}{|l|}{ Treatment Line } \\
\hline First & 13 & 5 & 5 & 3 \\
\hline Second & 10 & 0 & 5 & 5 \\
\hline Third or more & 6 & 3 & 2 & 1 \\
\hline \multicolumn{5}{|l|}{ Immune checkpoint inhibitor } \\
\hline Pembrolizumab & 17 & 5 & 7 & 5 \\
\hline Atezolizumab & 5 & 1 & 4 & 2 \\
\hline Nivolumab & 5 & 2 & 1 & 2 \\
\hline \multicolumn{5}{|l|}{ Body mass index $\left(\mathrm{kg} / \mathrm{m}^{2}\right)$} \\
\hline Mean \pm S/D & $22.7 \pm 4.0$ & $20.5 \pm 1.1$ & $22.5 \pm 4.0$ & $24.5 \pm 4.5$ \\
\hline \multicolumn{5}{|l|}{ Laboratory data $($ Mean $\pm S / D)$} \\
\hline NLR & $4.9 \pm 3.3$ & $7.7 \pm 5.0$ & $3.9 \pm 1.3$ & $3.8 \pm 1.7$ \\
\hline Lymphocyte $(/ \mu \mathrm{l})$ & $1220 \pm 456$ & $919 \pm 523$ & $1293 \pm 355$ & $1390 \pm 427$ \\
\hline $\mathrm{CRP}(\mathrm{mg} / \mathrm{dl})$ & $2.6 \pm 3.6$ & $5.8 \pm 5.2^{\dagger}$ & $2.2 \pm 2.1$ & $0.5 \pm 0.8$ \\
\hline Serum albumin $(\mathrm{g} / \mathrm{dl})$ & $3.8 \pm 0.6$ & $3.3 \pm 0.6^{\ddagger}$ & $3.8 \pm 0.5$ & $4.2 \pm 0.3$ \\
\hline
\end{tabular}

aepidermal growth factor receptor exon 19 deletion; NLR: neutrophil-to-lymphocyte ratio; CRP: C-reactive protein; S/D: standard deviation. ${ }^{\dagger}$ Group

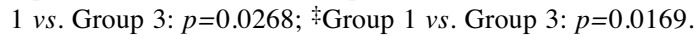

treatment on July 23, 2018 and the last patient received treatment on February 26, 2019. The patient demographics are shown in Table I.

IGRA results. As shown in Figure 1 , IFN- $\gamma$ levels in TB1, $\mathrm{TB} 2$, and the NC changed did not differ significantly between the sampling points except for five patients (one patient was an overlap case). Figure $1 \mathrm{~A}$ and $\mathrm{B}$ shows that two of these patients had changes in IFN- $\gamma$ levels at the TB1 and TB2 samples or only at the TB1 sample. One patient was diagnosed as having squamous NSCLC with active pulmonary MTB. Since $M T B$ patients with severe complications such as lung cancer often require longer courses of $M T B$ treatment than those without, he received long-term anti-MTB chemotherapy 
A

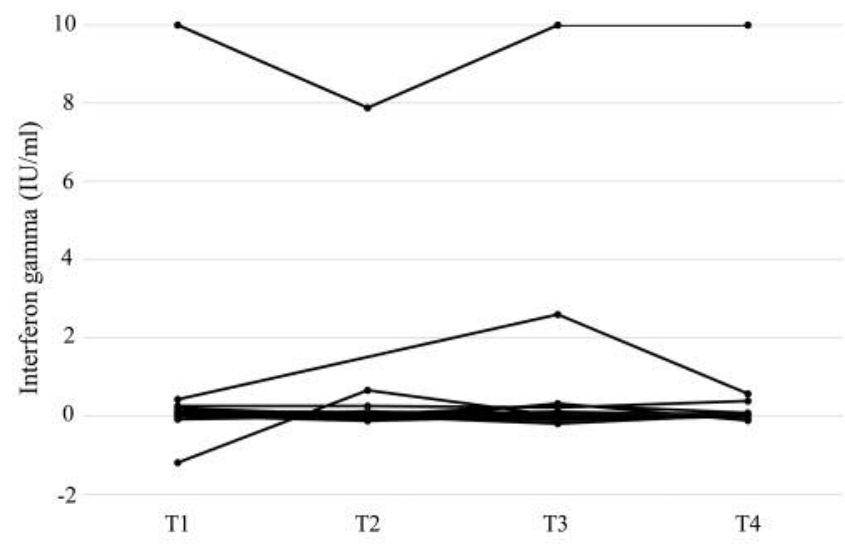

B

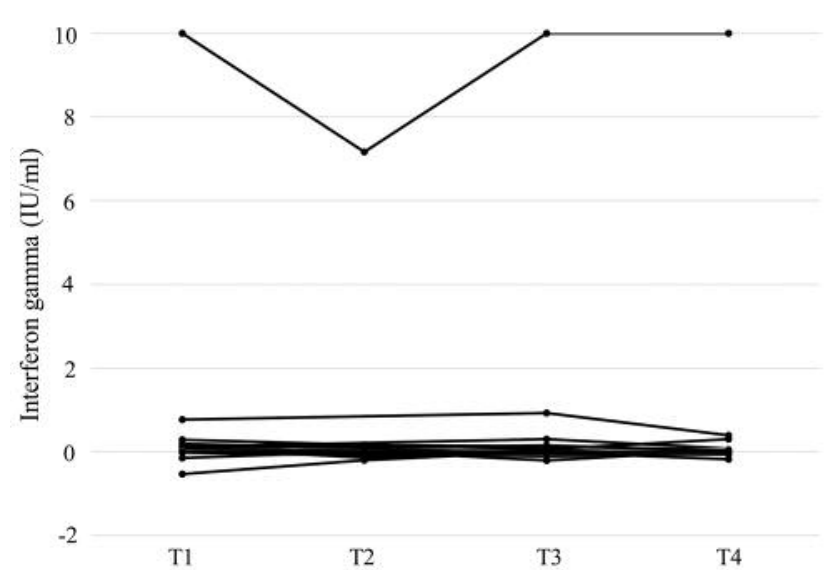

C

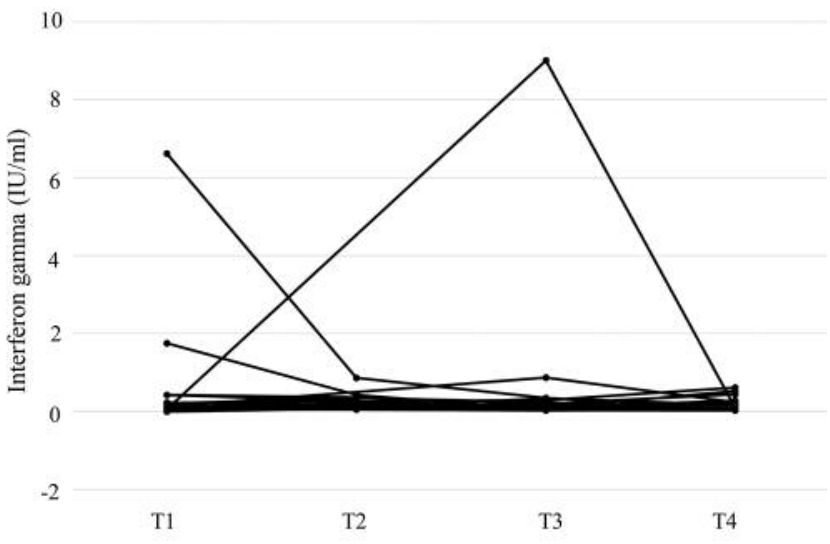

D

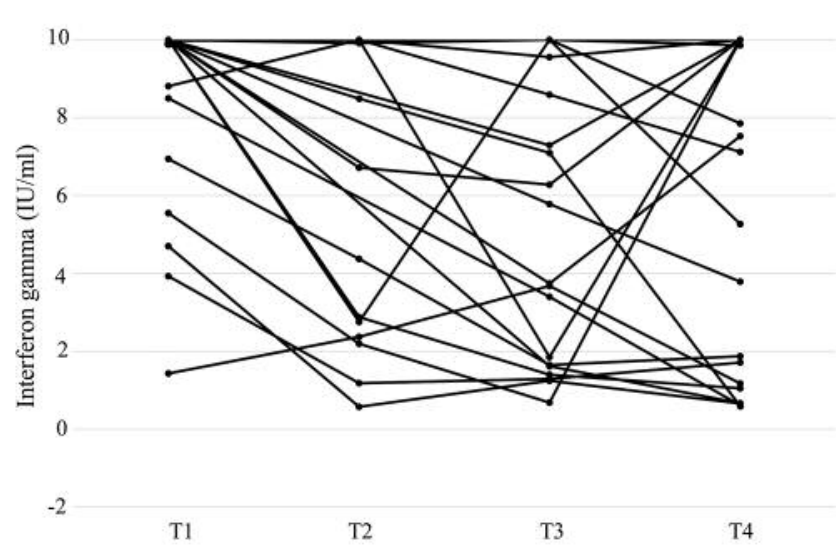

Figure 1. Polygonal line graphs of interferon-gamma $(I F N-\gamma)$ levels in patients receiving immune checkpoint inhibitors. A, Polygonal line graph of IFN- $\gamma$ levels for TB1. One patient with both squamous non-small cell lung cancer and active pulmonary Mycobacterium tuberculosis infection showed a transient decrease in IFN- $\gamma$ levels at T2. Another patient showed a transient increase at T3. B, Polygonal line graph of IFN- $\gamma$ levels for TB2. Same patient as in part A showed a similar, transient decrease at T2. C, Polygonal line graph of IFN- $\gamma$ levels in the negative control. One patient showed a rapid increase in IFN- $\gamma$ levels at T3 and simultaneously experienced a rapid progression of liver metastases with Grade 2 continuous fever. Two patients showed increased IFN- $\gamma$ levels at T1, which rapidly decreased at T2 to T4. D, Polygonal line graph of IFN- $\gamma$ levels in the positive control. According to IFN- $\gamma$ levels in the positive control, patients were categorized into three groups: patients $(n=8)$ with $<10$ IU/ml at T1, those (n=12) with $<10 \mathrm{IU} / \mathrm{ml}$ at T3 and/or T4, and those $(n=9)$ without changes in IFN- $\gamma$ levels. Each line in the plots represents one patient.

according to the American Thoracic Society and Infectious Diseases Society of America guidelines (19) from July 17, 2017 to April 22, 2019. He received a left upper lobe resection on September 13, 2017 and adjuvant chemotherapy from November 1, 2017 to February 4, 2018. Because of cancer progression, he concurrently received pembrolizumab and anti-MTB agents from November 27, 2018. After starting the anti-MTB chemotherapy, his sputum $M T B$ culture remained negative. He demonstrated a transient decrease in IFN- $\gamma$ levels after pembrolizumab treatment as follows: $\geq 10,7.88, \geq 10$, and $\geq 10 \mathrm{IU} / \mathrm{ml}$ for $\mathrm{TB} 1$, and $\geq 10,7.17, \geq 10$, and $\geq 10 \mathrm{IU} / \mathrm{ml}$ for $\mathrm{TB} 2$ at T1, T2, T3, and T4, respectively. Afterwards, he did not experience $M T B$ recurrence. The other patient had high IFN- $\gamma$ levels $(2.60 \mathrm{IU} / \mathrm{ml})$ in TB1 at T3. Subsequently, IFN- $\gamma$ levels were decreased to $0.57 \mathrm{IU} / \mathrm{ml}$ at $\mathrm{T} 4$. This patient did not develop MTB. As shown in Figure 1C, three patients presented with high IFN- $\gamma$ levels in NC at T1 and T3. Of them, one patient presented with high IFN- $\gamma$ levels $(9.01 \mathrm{IU} / \mathrm{ml})$ for $\mathrm{NC}$ at T3; this patient simultaneously experienced a rapid progression of liver metastases with Grade 2 continuous fever. 
Table II. Immune-related adverse events grouped according to interferon-gamma status in positive control.

\begin{tabular}{|c|c|c|c|c|c|c|c|c|c|c|c|c|}
\hline & \multicolumn{3}{|c|}{ Total $(n=29)$} & \multicolumn{3}{|c|}{ Group-1 (n=8) } & \multicolumn{3}{|c|}{ Group-2 $(\mathrm{n}=12)$} & \multicolumn{3}{|c|}{ Group $-3(n=9)$} \\
\hline \multicolumn{13}{|l|}{$\begin{array}{l}\text { Number of patients with immune-related } \\
\text { adverse events }(\%)\end{array}$} \\
\hline Yes & \multicolumn{3}{|c|}{$16(55.2)$} & \multicolumn{3}{|c|}{$4(50.0)$} & \multicolumn{3}{|c|}{$8(66.7)$} & \multicolumn{3}{|c|}{$4(44.4)$} \\
\hline No & \multicolumn{3}{|c|}{$13(44.8)$} & \multicolumn{3}{|c|}{$4(50.0)$} & \multicolumn{3}{|c|}{$4(33.3)$} & \multicolumn{3}{|c|}{$5(55.6)$} \\
\hline \multicolumn{13}{|l|}{$\begin{array}{l}\text { Number of patients according to } \\
\text { immune-related adverse events ( } n \text { ) }\end{array}$} \\
\hline Grade of immune-related adverse events ${ }^{\mathrm{a}}$ & 1 & 2 & $\geq 3$ & 1 & 2 & $\geq 3$ & 1 & 2 & $\geq 3$ & 1 & 2 & $\geq 3$ \\
\hline Fever & 4 & 1 & 0 & 0 & 0 & 0 & 2 & 1 & 0 & 2 & 0 & 0 \\
\hline Eruption & 6 & 1 & 0 & 2 & 1 & 0 & 3 & 0 & 0 & 1 & 0 & 0 \\
\hline Diarrhea & 1 & 2 & 0 & 0 & 0 & 0 & 1 & 1 & 0 & 0 & 1 & 0 \\
\hline Interstitial pneumonitis & 1 & 2 & 2 & 1 & 0 & 0 & 0 & 2 & 2 & 0 & 0 & 0 \\
\hline Thyroid disorder & 7 & 0 & 0 & 2 & 0 & 0 & 2 & 0 & 0 & 3 & 0 & 0 \\
\hline Diabetes mellitus & 0 & 0 & 1 & 0 & 0 & 1 & 0 & 0 & 0 & 0 & 0 & 0 \\
\hline
\end{tabular}

aThere were no treatment-related deaths.

After administration of corticosteroid, the fever improved with a decrease in IFN- $\gamma$ levels in $\mathrm{NC}$ at $\mathrm{T} 4$. In the remaining two patients, the IFN- $\gamma$ levels in NC increased to 6.62 and 1.75 $\mathrm{IU} / \mathrm{ml}$ at $\mathrm{T} 1$. The former was the same patient who concurrently received pembrolizumab and anti-MTB chemotherapy, as mentioned above. The later did not have specific disease complications. In these two patients, IFN- $\gamma$ levels in $\mathrm{NC}$ decreased to 0.86 and $0.43 \mathrm{IU} / \mathrm{ml}$ at $\mathrm{T} 2$, respectively. The IFN- $\gamma$ levels in the other 25 patients did not change for TB1, TB2, and NC, through all sampling points.

In contrast, as shown in Figure 1D, the IFN- $\gamma$ levels for PC varied before and after ICI treatments. The patients were divided into three groups according to these IFN- $\gamma$ levels as follows: Group-1 (Gr-1, n=8) with $<10 \mathrm{IU} / \mathrm{ml}$ at T1, Group-2 $(\mathrm{Gr}-2, \mathrm{n}=12)$ with at least one decrease to $<10 \mathrm{IU} / \mathrm{ml}$ at $\mathrm{T} 3$ and/or T4, and Group-3 (Gr-3, n=9) with no changes in IFN- $\gamma$ levels. One patient with IFN- $\gamma$ levels that transiently decreased to $9.92 \mathrm{IU} / \mathrm{ml}$ for PC at only T2 was categorized as Gr-3.

Patient demographics and laboratory data according to IFN$\gamma$ status in PC before ICI treatments. As shown in Table I, among the three groups, the performance status of 2 tended to be more frequently observed in Gr-1 than in the other groups. The mean BMI, lymphocyte count, and serum albumin tended to be lower in Gr-1 than in the other groups. The NLR was higher in Gr-1 than in the other groups. The mean CRP was significantly higher in Gr-1 than in Gr-3 $(p=0.0268)$ and it tended to be higher in Gr-1 than in Gr-2 . The mean serum albumin was significantly lower in Gr-1 than in Gr-3 $(p=0.0169)$ and it tended to be lower in Gr-1 than in Gr-2. None of the patients had autoimmune disease. Three of the 29 patients took corticosteroid and all of the three belonged to $\mathrm{Gr}-3$. Of the three, one patient took $10 \mathrm{mg}$ hydrocortisone for supplementation of adrenal dysfunction due to cytotoxic agents, one received $5 \mathrm{mg}$ prednisolone for pemetrexed-induced interstitial pneumonitis that developed 11 months ago, and the other patient $5 \mathrm{mg}$ prednisolone for chronic urticaria.

Immune-related adverse events according to IFN- $\gamma$ status in $P C$. Table II shows immune-related adverse events (irAEs) according to IFN- $\gamma$ status in the PC. The number of patients with irAEs and the number of irAEs were greater in Gr-2 than in the other groups. In particular, ICI-induced interstitial pneumonitis (ICI-IP) developed in five patients (17.2\%), and specifically in four patients in Gr-2.

Computed tomography findings, BAL, and TBLB. BAL and TBLB were performed for three of the five patients with ICIIP. Of these three patients, one was in Gr-1 (Case 1) and two were in Gr-2 (Cases 2 and 3).

Figure 2 shows the computed tomography findings before and after ICI treatment, and the pathological findings for Case 1 (Figure 2A, B, and C), Case 2 (Figure 2D, E, and F), and Case 3 (Figure 2G, H, and I). In Case 1, Grade 1 ICI-IP developed 29 days after starting atezolizumab. The BAL findings were as follows: a cell count of $44.0 \times 10^{5} / \mathrm{ml}$; macrophages $35.4 \%$, lymphocytes $52.8 \%$, neutrophils $6.3 \%$, and eosinophils $4.3 \%$; and a CD4/CD8 ratio of 2.94. A TBLB specimen obtained from the left bronchus $3 a$ (lt-B3a) and lt-B4a is shown in Figure 2C. The BMI, NLR, CRP, and serum albumin before ICI treatment were $24.5 \mathrm{~kg} / \mathrm{m}^{2}, 4.16$, $1.87 \mathrm{mg} / \mathrm{dl}$, and $3.3 \mathrm{~g} / \mathrm{dl}$, respectively. This patient has been followed up without receiving corticosteroid.

In Case 2, Grade 2 ICI-IP developed 37 days after starting atezolizumab. The BAL findings were as follows: a cell count of $10.5 \times 10^{5} / \mathrm{ml}$; macrophages $41.6 \%$, lymphocytes $56.1 \%$, neutrophils $1.2 \%$, and eosinophils $1.0 \%$; and a CD4/CD8 ratio 
A

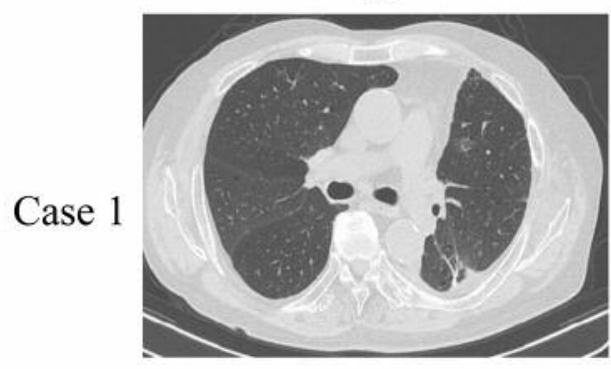

D

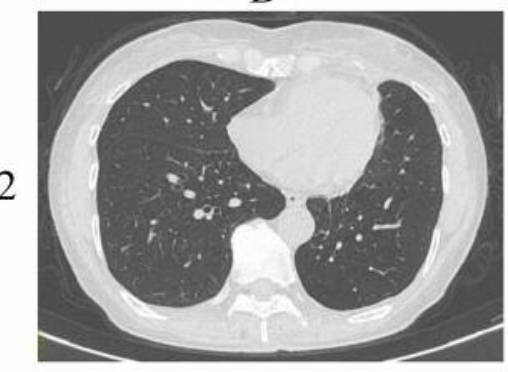

G

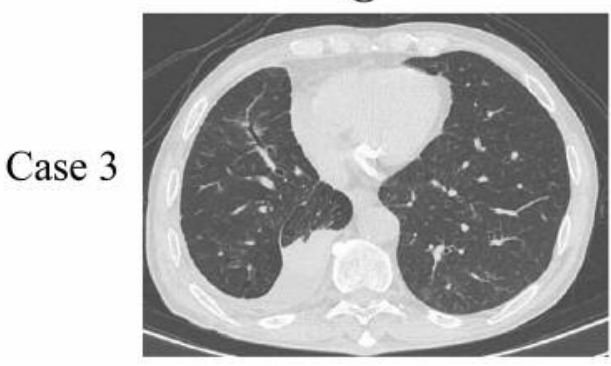

B

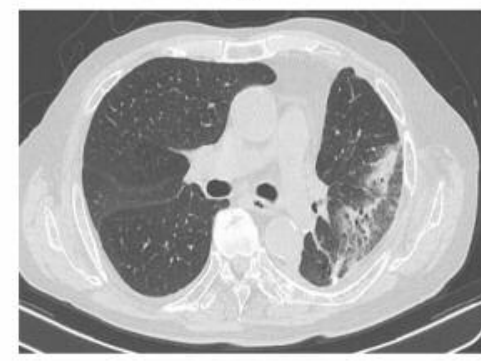

E

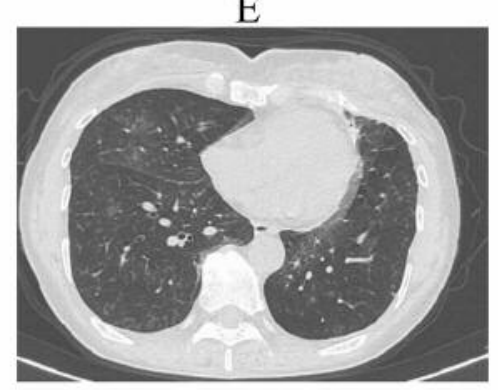

$\mathrm{H}$

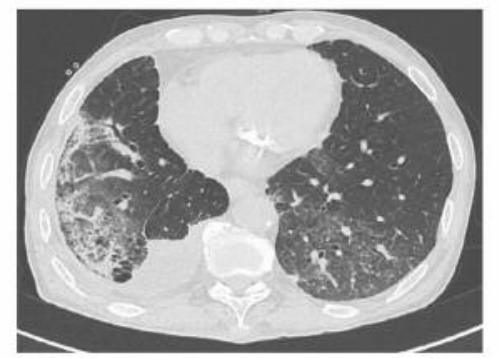

C

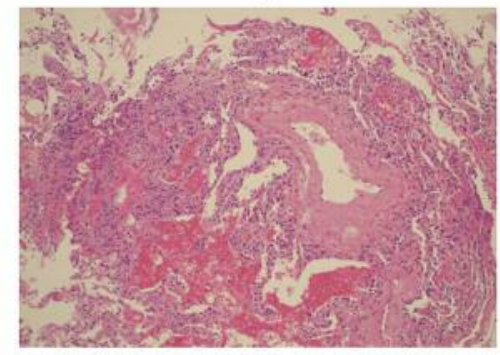

$\mathrm{F}$

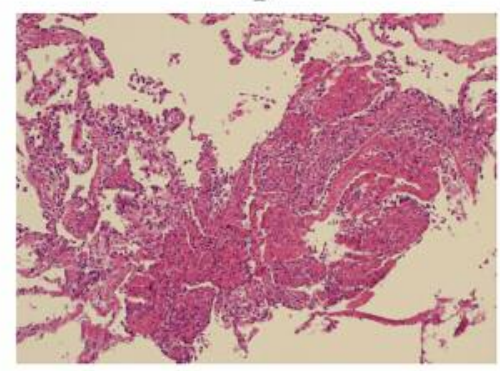

I

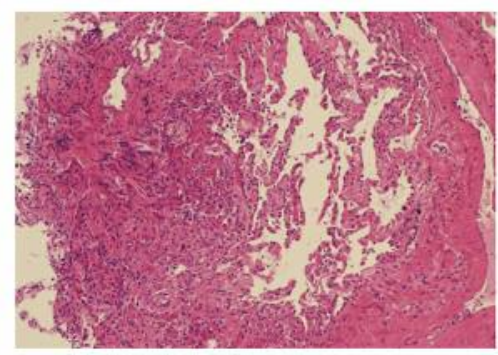

Figure 2. Chest computed tomography (CT) scan findings and pathological findings of transbronchial lung biopsies. Case 1: A, Chest CT image before atezolizumab treatment. B, Chest CT image on day 29 of nivolumab treatment revealed ground grass opacity with linear consolidation in left residual lung after surgery. C, Pathological finding [Hematoxylin-Eosin staining (HE), x100 magnification] mimicked organizing pneumonia with intra-alveolar collection of foamy cells and proliferation of atypical type II pneumocytes. Case 2: D, Chest CT image before atezolizumab treatment. E, Chest CT image on day 37 of atezolizumab treatment revealed diffuse ground grass opacity in both right lower lobe and left residual lung after surgery. F, Pathological finding (HE, ×100 magnification) showed pneumonia with apparent intra-alveolar exudates and infiltration of neutrophils. Case 3: G, Chest CT image before pembrolizumab treatment. $H$, Chest CT image on day 62 of pembrolizumab treatment revealed diffuse ground grass opacity with consolidation in right lung and diffuse ground grass opacity in left lung. I, Pathological finding (HE, $\times 100$ magnification) showed organizing pneumonia with granulation tissue in the lumen of alveolar ducts and collection of macrophages in alveolar cavities.

of 2.94. A TBLB specimen obtained from right bronchus $8 \mathrm{a}$ (rt-B8a), rt-B9a, and rt-B2b is shown in Figure $2 \mathrm{~F}$. Pathological analysis revealed pneumonia with apparent intraalveolar exudate; however, we diagnosed this patient with ICI-IP based on the chest CT scan and BAL findings. The BMI, NLR, CRP, and serum albumin before ICI treatment were $19.9 \mathrm{~kg} / \mathrm{m}^{2}, 4.13,0.9 \mathrm{mg} / \mathrm{dl}$, and $4.2 \mathrm{~g} / \mathrm{dl}$, respectively. This patient received orally $30 \mathrm{mg}$ prednisolone. Afterwards, the ICI-IP improved without inflammatory scarring.

In Case 3, Grade 3 ICI-IP developed 62 days after starting pembrolizumab. The BAL findings were as follows: a cell count of $19.5 \times 10^{5} / \mathrm{ml}$; macrophages $25.2 \%$, lymphocytes $20.5 \%$, neutrophils $42.6 \%$, and eosinophils $10.1 \%$; and a CD4/CD8 ratio of 1.87. A TBLB specimen obtained from rt-B8a, rt-B9a, and rt-B2b is shown in Figure 2I. The BMI, NLR, CRP, and serum albumin before ICI treatment were $21.6 \mathrm{~kg} / \mathrm{m}^{2}, 2.71$, $6.22 \mathrm{mg} / \mathrm{dl}$, and $2.9 \mathrm{~g} / \mathrm{dl}$, respectively. Since an intravenous pulse therapy with methylprednisolone $1000 \mathrm{mg}$ /day for three consecutive days was not effective, this patient received cyclophosphamide pulse therapy $(750 \mathrm{mg} /$ day $)$, as in a previous study (20). Afterwards, the ICI-IP improved with inflammatory scarring. 
Table III. Efficacy of immune checkpoint inhibitors grouped according to interferon-gamma status in positive control.

\begin{tabular}{lcccc}
\hline & Total $(\mathrm{n}=29)$ & Group-1 $(\mathrm{n}=8)$ & Group-2 $(\mathrm{n}=12)$ & Group-3 $(\mathrm{n}=9)$ \\
\hline Best response $(\mathrm{n})(\%)$ & & & & 0 \\
Complete response & 0 & 0 & $3(25.0)$ & $1(11.1)$ \\
Partial response & $4(13.8)$ & 0 & $4(33.3)$ & $5(55.6)$ \\
Stable disease & $9(31.0)$ & 0 & $5(41.7)$ & $3(33.3)$ \\
Progressive disease & $15(51.7)$ & $1(87.5) \dagger$ & 0 \\
$\quad$ Not evaluable & $1(3.4)$ & 0 & 25.0 & 11.1 \\
Response rate (\%) & 13.8 & $2(1-5)$ & $3(1-8)$ & $4(3-12)^{\ddagger}$ \\
Treatment cycles & & & \\
Median (range) & $3(1-12)$ & & \\
\hline
\end{tabular}

${ }^{a}$ Number of treatment cycles was counted until May 31, 2019. ${ }^{\dagger}$ Group 1 vs. Group 2: $p=0.0498 ; ~ ‡$ Group 1 vs. Group 3: $p=0.0080$.

Efficacy of ICIs according to IFN- $\gamma$ status in PC. As shown in Table III, the response rate (\%) was $13.8,0,25.0$, and 11.1 in all patients in Gr-1, Gr-2, and Gr-3, respectively. The frequency of PD in Gr-1 $(87.5 \%)$ was significantly higher than that in $\mathrm{Gr}-3(33.3 \%)(p=0.0498)$ and it tended to be higher in Gr-1 than in Gr-2 (41.7\%) ( $p=0.0697)$. Especially, early progression was frequently observed in Gr-1. The number of treatment cycles [median (range)] in all patients, in Gr-1, Gr-2, and Gr-3 was 3 (1-12), 2 (1-5), 3 (1-8), and 4 (3-12), respectively. Gr-3 received significantly more ICI treatment cycles than Gr-1 $(p=0.0080)$ and it tended to receive more than $\mathrm{Gr}-2(p=0.092)$.

\section{Discussion}

This preliminary study aimed to verify our hypothesis that IFN- $\gamma$ release from $\mathrm{T}$ lymphocyte would change after ICI treatment and to examine the usefulness of IFN- $\gamma$ as biomarker for ICI treatment. Thus, we first reported that IFN- $\gamma$ levels in the PC were dynamically changed after ICI treatment. According to the IFN- $\gamma$ levels in the PC, the 29 NSCLC patients who received ICIs were divided into three groups. Gr-1 tended to have a higher level of both NLR and CRP and a lower level of both BMI and serum albumin than the other groups. Patients in Gr-1 with a PC of $<10 \mathrm{IU} / \mathrm{ml}$ before treatment may have a poor immunological status including cancer-associated inflammation and malnutrition, as described in our previous study (21). Despite the fact that $62.5 \%$ of patients in Gr-1 had a PD-L1 Tumor Proportion Score $\geq 50 \%$, seven patients $(87.5 \%)$ in Gr-1 developed early cancer progression as mentioned previously (21). In Gr-2, IFN- $\gamma$ levels were decreased after ICI treatment. Therefore, we hypothesize that the $\mathrm{T}$ lymphocytes are excessively activated in the tumor immune microenvironment by ICI treatment and overflow into the peripheral blood; they will not respond to PHA in the PC because they are already activated. These $\mathrm{T}$ lymphocytes would affect not only lung cancer but also various organs, especially the lungs. In Gr3 , IFN- $\gamma$ levels were unchanged in the PC after ICI treatment. Therefore, we hypothesize that the $\mathrm{T}$ lymphocytes are not excessively activated in the tumor immune microenvironment and do not overflow into the peripheral blood. As a result, the patients in Gr-3 did not show severe irAEs and obvious responses. Some patients in Gr-3 continued with more treatment cycles than patients in the other groups. In this scenario, monitoring changes in the QFT-Plus PC would be useful for predicting the clinical course of patients treated with ICIs. In particular, patients with $<10 \mathrm{IU} / \mathrm{ml}$ in the PC before treatment should avoid ICI treatment until cancer-associated inflammation and malnutrition have improved.

The immunological responses of the three groups in this study resemble the "damage-response framework" against pathogens described by Casadevall and Pirofski (22), especially with $M T B$. They have indicated that too strong immunoreactions and too weak immunoreactions result in death of the host, but an appropriate immunoreaction results in a positive outcome for the host. In this study, the immunoreaction in Gr-3 may be an appropriate damageresponse, which is important for better outcomes during ICI treatments. Teraoka et al. (23) have reported an appropriate damage-response so that early irAEs were associated with better outcomes after ICI treatment. Our patients in Gr-1 were immunosuppressed, leading to early progression, and those in Gr-2 had excessive immune responses, leading to favorable treatment responses and severe irAEs.

In the present study, the incidence of ICI-IP was $17.2 \%$, which is higher than that reported in previous studies (24-26). However, a recent report by Suresh et al. (27) has indicated that $39(19.0 \%)$ of 205 patients with advanced NSCLC experienced ICI-IP, similar to the percentage in our study. Suresh et al. have hypothesized that the increased incidence was partially explained by a greater awareness of this entity and increased pharmacovigilance with ICI administration. In 
our study, 4 out of 5 patients with ICI-IP belonged to Gr-2. These results suggest that decreased IFN- $\gamma$ levels in the PC after ICI treatment would be a useful marker for the early detection of ICI-IP. Furthermore, in our study, the mean CRP before ICI treatment was significantly higher in Gr-1 than in Gr-3 and it tended to be higher in Gr-1 than in Gr-2. In addition, the mean serum albumin before ICI treatment was significantly lower in Gr-1 than in Gr-3 and it tended to be lower in Gr-1 than in Gr-2. Gr-1 and Gr-2 represent a poorer immunological status than Gr-3. The incidence of ICI-IP in clinical practice may be higher than that in clinical trials because of higher numbers of patients with cancer-associated inflammation and malnutrition. Thus, the IFN- $\gamma$ levels in the QFT-Plus PC before ICI treatment may be useful for the detection of a poor immunological status, including cancerassociated inflammation and malnutrition.

However, in a later publication, Suresh et al. (28) have reported that developing ICI-IP increased the risk of death, unlike extrapulmonary irAEs. Using experimental mouse models, Sakai et al. (9) have found that there was a difference in the contribution of IFN- $\gamma$ for protecting from $M T B$ infection between the lung and spleen (an extrapulmonary organ). Furthermore, they described that excessive IFN- $\gamma$ is less protective in the lungs and eventually drives lethal disease. This mechanism could serve as a reference for irAEs due to ICIs.

Our study has several limitations that must be considered. First, the sample size in this study was small. Second, the population of patients enrolled in this study was heterogeneous. Third, we could not identify IFN- $\gamma$ values of $\geq 10 \mathrm{IU} / \mathrm{ml}$ in the QFT-Plus assay. Fourth, we did not examine gene alterations such as tumor mutation burdens. Fifth, we did not examine cytokines and interleukins other than IFN- $\gamma$.

The above-mentioned limitations do raise questions about the usefulness of IFN- $\gamma$ as a biomarker of ICI treatment, therefore, in the future, we will examine its usefulness as a biomarker in a prospective study that addresses the limitations listed above.

\section{Conclusion}

Changes in the PD-1/PD-11 axis by ICI treatment affect INF$\gamma$ release by $\mathrm{T}$ lymphocytes. IFN- $\gamma$ levels assayed by IGRA using QFT-Plus could be a novel, biomarker for the early detection of severe irAEs, including ICI-IP, and for patient selection for ICI treatment.

\section{Conflicts of Interest}

T.H. received honoraria and research funding from Ono Pharmaceutical Co. Ltd. (Osaka, Japan), Lilly Japan Co. Ltd. (Hyogo, Japan), AstraZeneca Co. Ltd. (Osaka, Japan), Taiho Pharmaceutical Co. Ltd. (Tokyo, Japan), Chugai Pharmaceutical Co. Ltd. (Tokyo, Japan), Merck Serono Co. Ltd. (Tokyo, Japan), MSD Oncology Co. Ltd. (Tokyo, Japan), Kyowa-Hakko Kirin, and
Boehringer Ingelheim. The other Authors have no conflicts of interest to declare.

\section{Authors' Contributions}

All Authors were involved in the conception and design of the study, or acquisition of data, or analysis and interpretation of data; drafting the article or revising it critically for important intellectual content; and final approval of the version to be submitted. T.H., T.K, H.S., Y.S., Y.N., S.N., A.T, N.M., S.H., and N.O. collected clinical data. H.Y., A.M. and Y.T. performed measurement of QuantiFERON ${ }^{\circledR}$-TB Gold Plus. H.K. performed flow cytometry. K.K made a pathological diagnosis. T.H., T.K., H.S., and T.T. performed the statistical analyses.

\section{Acknowledgements}

The Authors thank Editage (www.editage.jp) for English language editing. The Authors would like to thank their patients.

\section{References}

1 Ishida Y, Agata Y, Shibahara K and Honjo T: Induced expression of pd-1, a novel member of the immunoglobulin gene superfamily, upon programmed cell death. EMBO J 11(11): 3887-3895, 1992. PMID: 1396582.

2 Brahmer JR, Drake CG, Wollner I, Powderly JD, Picus J, Sharfman WH, Stankevich E, Pons A, Salay TM, McMiller TL, Gilson MM, Wang C, Selby M, Taube JM, Anders R, Chen L, Korman AJ, Pardoll DM, Lowy I and Topalian SL: Phase I study of single-agent anti-programmed death-1 (mdx-1106) in refractory solid tumors: Safety, clinical activity, pharmacodynamics, and immunologic correlates. J Clin Oncol 28(19): 3167-3175, 2010. PMID: 20516446. DOI: 10.1200/JCO.2009. 26.7609

3 Gandhi L, Rodriguez-Abreu D, Gadgeel S, Esteban E, Felip E, De Angelis F, Domine M, Clingan P, Hochmair MJ, Powell SF, Cheng SY, Bischoff HG, Peled N, Grossi F, Jennens RR, Reck M, Hui R, Garon EB, Boyer M, Rubio-Viqueira B, Novello S, Kurata T, Gray JE, Vida J, Wei Z, Yang J, Raftopoulos H, Pietanza MC, Garassino MC and KEYNOTE-189 Investigators: Pembrolizumab plus chemotherapy in metastatic non-small-cell lung cancer. N Engl J Med 378(22): 2078-2092, 2018. PMID: 29658856. DOI: $10.1056 /$ NEJMoa 1801005

4 Paz-Ares L, Luft A, Vicente D, Tafreshi A, Gumus M, Mazieres J, Hermes B, Cay Senler F, Csoszi T, Fulop A, Rodriguez-Cid J, Wilson J, Sugawara S, Kato T, Lee KH, Cheng Y, Novello S, Halmos B, Li X, Lubiniecki GM, Piperdi B, Kowalski DM and KEYNOTE-407 Investigators: Pembrolizumab plus chemotherapy for squamous non-small-cell lung cancer. N Engl J Med 379(21): 2040-2051, 2018. PMID: 30280635. DOI: 10.1056/NEJMoa1810865

5 Socinski MA, Jotte RM, Cappuzzo F, Orlandi F, Stroyakovskiy D, Nogami N, Rodriguez-Abreu D, Moro-Sibilot D, Thomas CA, Barlesi F, Finley G, Kelsch C, Lee A, Coleman S, Deng Y, Shen Y, Kowanetz M, Lopez-Chavez A, Sandler A, Reck M and Group IMS: Atezolizumab for first-line treatment of metastatic nonsquamous NSCLC. N Engl J Med 378(24): 2288-2301, 2018. PMID: 29863955. DOI: 10.1056/NEJMoa1716948 
6 Herbst RS, Baas P, Kim DW, Felip E, Perez-Gracia JL, Han JY, Molina J, Kim JH, Arvis CD, Ahn MJ, Majem M, Fidler MJ, de Castro G, Jr., Garrido M, Lubiniecki GM, Shentu Y, Im E, Dolled-Filhart $\mathrm{M}$ and Garon EB: Pembrolizumab versus docetaxel for previously treated, pd-11-positive, advanced nonsmall-cell lung cancer (keynote-010): A randomised controlled trial. Lancet 387(10027): 1540-1550, 2016. PMID: 26712084 DOI: $10.1016 / \mathrm{S} 0140-6736(15) 01281-7$

7 Takata S, Koh G, Han Y, Yoshida H, Shiroyama T, Takada H, Masuhiro K, Nasu S, Morita S, Tanaka A, Hashimoto S, Uriu K, Suzuki H, Tamura Y, Okamoto N, Nagai T and Hirashima T: Paradoxical response in a patient with non-small cell lung cancer who received nivolumab followed by anti-mycobacterium tuberculosis agents. J Infect Chemother 25(1): 54-58, 2019. PMID: 30055859. DOI: 10.1016/j.jiac.2018.06.016

8 Barber DL, Mayer-Barber KD, Feng CG, Sharpe AH and Sher A: $\mathrm{Cd} 4 \mathrm{t}$ cells promote rather than control tuberculosis in the absence of pd-1-mediated inhibition. J Immunol 186(3): 15981607, 2011. PMID: 21172867. DOI: 10.4049/jimmunol. 1003304

9 Sakai S, Kauffman KD, Sallin MA, Sharpe AH, Young HA, Ganusov VV and Barber DL: Cd4 t cell-derived ifn-gamma plays a minimal role in control of pulmonary mycobacterium tuberculosis infection and must be actively repressed by pd-1 to prevent lethal disease. PLoS Pathog 12(5): e1005667, 2016. PMID: 27244558. DOI: 10.1371/journal.ppat.1005667

10 Tousif S, Singh Y, Prasad DV, Sharma P, Van Kaer L and Das G: $\mathrm{T}$ cells from programmed death-1 deficient mice respond poorly to mycobacterium tuberculosis infection. PLoS One 6(5): e19864, 2011. PMID: 21589883. DOI: 10.1371/journal.pone.0019864

11 World Health Organization. Use of tuberculosis interferon-gamma release assays (IGRAs) in low- and middle-income countries: policy statement. Available at: https://apps.who.int/iris/handle/10665/44759 (last accessed June 18, 2019).

12 Quiagen. QuantiFERON-TB Gold Plus. Available at: https://www.qiagen.com/us/products/diagnostics-and-clinicalresearch/tb-management/quantiferon-tb-gold-plus/quantiferon-tbgold-plus-us/\#productdetails (last accessed June 18, 2019)

13 Shearer WT, Dunn E, Notarangelo LD, Dvorak CC, Puck JM, Logan BR, Griffith LM, Kohn DB, O'Reilly RJ, Fleisher TA, Pai SY, Martinez CA, Buckley RH and Cowan MJ: Establishing diagnostic criteria for severe combined immunodeficiency disease (scid), leaky scid, and omenn syndrome: The primary immune deficiency treatment consortium experience. J Allergy Clin Immunol 133(4): 1092-1098, 2014. PMID: 24290292. DOI: 10.1016/j.jaci.2013.09.044

14 National Cancer Institution. Common Terminology Criteria for Adverse Events (CTCAE) v4.0. Available at: https://ctep. cancer.gov/protocolDevelopment/electronic_applications/ctc.htm \#ctc_40 (last accessed June 18 2019)

15 Fukushima PI, Nguyen PK, O'Grady P and Stetler-Stevenson M: Flow cytometric analysis of kappa and lambda light chain expression in evaluation of specimens for b-cell neoplasia. Cytometry 26(4): 243-252, 1996. PMID: 8979022. DOI: 10.1002/(SICI) 1097-0320(19961215)26:4<243::AIDCYTO2>3.0.CO;2-D.

16 British Thoracic Society Bronchoscopy Guidelines Committee aSoSoCCoBTS: British thoracic society guidelines on diagnostic flexible bronchoscopy. Thorax 56: i1-21, 2001. PMID: 11158709. DOI: 10.1136/thorax.56.suppl_1.i1
17 Ferrara R, Mezquita L, Texier M, Lahmar J, Audigier-Valette C, Tessonnier L, Mazieres J, Zalcman G, Brosseau S, Le Moulec S, Leroy L, Duchemann B, Lefebvre C, Veillon R, Westeel V, Koscielny S, Champiat S, Ferte C, Planchard D, Remon J, Boucher ME, Gazzah A, Adam J, Bria E, Tortora G, Soria JC, Besse B and Caramella C: Hyperprogressive disease in patients with advanced non-small cell lung cancer treated with pd-1/pd-11 inhibitors or with single-agent chemotherapy. JAMA Oncol 4(11): 1543-1552, 2018. PMID: 30193240. DOI: 10.1001/jamaoncol.2018.3676

18 R.C. Team, The R Project for Statistical Computing. Available at: https://www.r-project.org/ (last accessed June 18, 2019)

19 Blumberg HM, Burman WJ, Chaisson RE, Daley CL, Etkind SC, Friedman LN, Fujiwara P, Grzemska M, Hopewell PC, Iseman MD, Jasmer RM, Koppaka V, Menzies RI, O'Brien RJ, Reves RR, Reichman LB, Simone PM, Starke JR, Vernon AA, American Thoracic Society, Centers for Disease Control and Prevention and the Infectious Diseases Society: American thoracic society/centers for disease control and prevention/infectious diseases society of America: Treatment of tuberculosis. Am J Respir Crit Care Med 167(4): 603-662, 2003. PMID: 12588714. DOI: 10.1164/ rccm.167.4.603

20 Yoshida T, Koga H, Saitoh F, Sakamoto M, Harada M, Yoshida H, Sakisaka S and Sata M: Pulse intravenous cyclophosphamide treatment for steroid-resistant interstitial pneumonitis associated with polymyositis. Intern Med 38(9): 733-738, 1999. PMID: 10480306. DOI: 10.2169/internalmedicine.38.733

21 Shiroyama T, Suzuki H, Tamiya M, Tamiya A, Tanaka A, Okamoto N, Nakahama K, Taniguchi Y, Isa SI, Inoue T, Imamura $\mathrm{F}$, Atagi $\mathrm{S}$ and Hirashima T: Pretreatment advanced lung cancer inflammation index (ali) for predicting early progression in nivolumab-treated patients with advanced nonsmall cell lung cancer. Cancer Med 7(1): 13-20, 2018. PMID: 29150906. DOI: $10.1002 /$ cam4.1234

22 Casadevall A and Pirofski LA: The damage-response framework of microbial pathogenesis. Nat Rev Microbiol 1(1): 17-24, 2003. PMID: 15040176. DOI: 10.1038/nrmicro732

23 Teraoka S, Fujimoto D, Morimoto T, Kawachi H, Ito M, Sato Y, Nagata K, Nakagawa A, Otsuka K, Uehara K, Imai Y, Ishida K, Fukuoka $\mathrm{J}$ and Tomii K: Early immune-related adverse events and association with outcome in advanced non-small cell lung cancer patients treated with nivolumab: A prospective cohort study. J Thorac Oncol 12(12): 1798-1805, 2017. PMID: 28939128. DOI: $10.1016 /$ j.jtho.2017.08.022

24 Kato T, Masuda N, Nakanishi Y, Takahashi M, Hida T, Sakai H, Atagi S, Fujita S, Tanaka H, Takeda K, Satouchi M, Namba $\mathrm{Y}$ and Tamura T: Nivolumab-induced interstitial lung disease analysis of two phase II studies patients with recurrent or advanced non-small-cell lung cancer. Lung Cancer 104: 111118, 2017. PMID: 28212992. DOI: 10.1016/j.lungcan. 2016.12.016

25 Brahmer J, Reckamp KL, Baas P, Crino L, Eberhardt WE, Poddubskaya E, Antonia S, Pluzanski A, Vokes EE, Holgado E, Waterhouse D, Ready N, Gainor J, Aren Frontera O, Havel L, Steins M, Garassino MC, Aerts JG, Domine M, Paz-Ares L, Reck M, Baudelet C, Harbison CT, Lestini B and Spigel DR: Nivolumab versus docetaxel in advanced squamous-cell nonsmall-cell lung cancer. N Engl J Med 373(2): 123-135, 2015. PMID: 26028407. DOI: 10.1056/NEJMoa1504627

26 Borghaei H, Paz-Ares L, Horn L, Spigel DR, Steins M, Ready NE, Chow LQ, Vokes EE, Felip E, Holgado E, Barlesi F, 
Kohlhaufl M, Arrieta O, Burgio MA, Fayette J, Lena H, Poddubskaya E, Gerber DE, Gettinger SN, Rudin CM, Rizvi N, Crino L, Blumenschein GR Jr., Antonia SJ, Dorange C, Harbison CT, Graf Finckenstein F and Brahmer JR: Nivolumab versus docetaxel in advanced nonsquamous non-small-cell lung cancer. N Engl J Med 373(17): 1627-1639, 2015. PMID: 26412456. DOI: 10.1056/NEJMoa1507643

27 Suresh K, Voong KR, Shankar B, Forde PM, Ettinger DS, Marrone KA, Kelly RJ, Hann CL, Levy B, Feliciano JL, Brahmer JR, Feller-Kopman D, Lerner AD, Lee H, Yarmus L, D'Alessio F, Hales RK, Lin CT, Psoter KJ, Danoff SK and Naidoo J: Pneumonitis in non-small cell lung cancer patients receiving immune checkpoint immunotherapy: Incidence and risk factors. J Thorac Oncol 13(12): 1930-1939, 2018. PMID: 30267842. DOI: $10.1016 /$ j.jtho.2018.08.2035
28 Suresh K, Psoter KJ, Voong KR, Shankar B, Forde PM, Ettinger DS, Marrone KA, Kelly RJ, Hann CL, Levy B, Feliciano JL, Brahmer JR, Feller-Kopman D, Lerner AD, Lee H, Yarmus L, Hales RK, D'Alessio F, Danoff SK and Naidoo J: Impact of checkpoint inhibitor pneumonitis on survival in NSCLC patients receiving immune checkpoint immunotherapy. J Thorac Oncol 14(3): 494-502, 2019. PMID: 30503891. DOI: 10.1016/j.jtho. 2018.11 .0

Received September 26, 2019

Revised October 9, 2019

Accepted October 10, 2019 